\title{
Colors in Gond Tribal Art: An interpretation and critical evaluation of Colors in Gond Paintings of Madhya Pradesh.
}

\author{
Dr. Kumkum Bharadwaj \\ Asstt. Professor, \\ Govt. M.L.B. Girls P.G. College, Indore \\ Anu Ukande \\ Research Scholar
}

\begin{abstract}
Fork-art forms have the great social mission of creating cultural identity. The integrity of individuals and equipping them to meet social challenges are a part of this. In Madhya Pradesh - the heart of India lies the oldest found art heritage in the world. Gond Tribal paintings of Madhya Pradesh have gained worldwide recognition in recent years. The Gond tribe, one of the largest Tribal communities of central India resides in Madhya Pradesh and Chhattisgarh. Over the past decades it has been observed that tribal people are being assimilated with the rest of the population and this process has been a continuous one. With the process of integration arise challenges of retaining, preserving and promoting the cultural elements of the tribes which may face the threat of extinction.

This paper attempts to analyze the changes in Gond art brought about by their gradual assimilation into mainstream arts, and the future approaches to colors.
\end{abstract}

\section{INTRODUCTION}

In the words of legendry artist J. Swaminathan, "It would indeed perhaps be convenient, if one were to undertake a study of tribal art, to locate it in communities as closed systems. Such, however, is not the case. In dealing with tribal art we are dealing with the art of peoples very much with us and of us, forming a sizeable part of our population, living under the same skies and on the same earth, though historical time seems to lie like an insurmountable barrier between us." 1 Bhopal first started attracting contemporary rural artists in the 1980s when its Bharat Bhavan museum was developed by the famous artist and cultural impresario J. Swaminathan. The region is famous for its folks and tribal cultures, yet until Swaminathan got involved, Indian museums knew little about talented artists living in the hinterlands. Swaminathan sent a team of urban art students out to scour the countryside to see what might be there. Unsurprisingly, they uncovered immense artistic talent. The challenge was to then convince these gifted regional artists to get involved with an institution in a distant big city.

One of the team's most celebrated discoveries was the Gond tribal artist Jangarh Singh Shyam. Born in the Mandla district of Madhya Pradesh, Jangarh's remote origins, unusual venture from Patangarh village to Bhopal, meteoric rise to international fame, and subsequent tragic death in Japan in 2001, has become one of the more extraordinary tales of contemporary Indian art. Several 
years before his death, curator Shah invited him to create an artwork to add to the outdoor Mythology Trail. Well known as a talented painter, Jangarh began experimenting with ceramics.

His legacy still thrives in Bhopal. Members of his extended family and other talented artists from Mandla have followed in his footsteps to produce dazzlingly colourful narrative pictures on paper, canvas and walls. Some of these artists have achieved international recognition. 2

\section{Culture:}

Many of the Gonds customs echo that of their Mesolithic forbearers. An obvious example of this is the custom of decorating the walls of their houses, an activity that may originate in cave-dwelling traditions of their ancestors.

The practice of wall and floor paintings in honor of religious celebrations as well as portrayal of customs is a tradition among all tribes of India. Gond villages follow a similar pattern and amongst all themes, it's the digna - painted on houses during weddings and other festive occasions - that's most popular. Perhaps one of the most poignant factors in the perception of colors in the Indian psyche is the religious undertones that coexist at almost every phase of an "Indian's life." Gond tribal walls come alive with vibrant depictions of local flora, fauna and gods such as Marahi Devi and Phulvari Devi (Goddess Kali). Traditionally made on festive occasions, Gond painting depicts various celebrations, rituals and man's relationship with nature. This mystical art form is created by putting together dots and lines. The imaginative use of the line imparts a sense of movement to the still images. They believe that good fortune befalls those whose eye meets a good image, so it is in the community's interest to be surrounded by beauty. The function of art for them isn't just restricted to practical and aesthetic pleasure; it also ensures a continuum between the past and the present, and in this sense the very act of painting is considered spiritual: an act of prayer.The paintings are not only an offering in worship of nature, but are also a mode of seeking protection and warding off evil.

\section{Themes:}

A narrative form of folk art, the vernacular of the soul is expressed in all the brilliant hues of Gondi art. The paintings transport you to the seamless world of the inspired and the surprising. They have a remarkable two dimensional style. The multi-hued, dot-bright grandeurs of tribal gods, fantastical birds, anthill-covered alligators and long-snouted crabs are both creative and imaginative.

Derived from Lore, the artists' immediate environment and more recently the exposure to urban culture, these paintings transport ideas in anunassuming, organic visual language, untouched by the layers of formal training.Their belief system is based on the sanctity of their environs - it being the source of their livelihood and survival. Their art is filled with their co - inhabitants viz animals, birds and insects, who occupy their legends, art and music.This permits them to create their own visual rules of engaging with themselves \& the onlooker. They construct their own color palettes, rules of perspective and composition.

What transpire are delightful art expressions, all in their own language. 
Gond art is based on the conviction that viewing a good image attracts good luck. They would thus decorate their houses and the floors with traditional tattoos and motifs, drawn during festivals or rituals connected with seasonal changes like sowing of crops, onset of rains, harvest or on a significant occasion in their families such as birth, marriage, pregnancy,death.

Gond- Pardhans believe in devayoni (divine form) and bhutayoni (ghost form). They believe in atman (soul). 3

The community draws positive energy by surrounding itself with color and art enthusedwith nature and everyday living. Gond art reverberates with a culturally distinct ethos and draws stimulation from myths and legends to images of daily life, the surrealism of sensations, aspirations and imagination. The mythical beasts and the intricate detailing of flora and fauna are the dominant themes that have animated the works of the Gonds The child like simplicity of these art works reflect the community's own straightforwardness.

The myriad interpretations of the artists' describing signature patterns create anabundance of aesthetic forms and styles. These signature styles are the spirit of this tribal art form and are used to fill the surface of their decorative designs. As we enter this special Gond cosmos, we will learn how the creator, BadaDeo, created trees from three strands of his body hair, coating them with ash so they could bear fruit and flower. We will learn of the many animals of the Gond forests - the diligent silkworms, the shifty chameleons, and the peacocks who with their alluring dances alter trees into flaming feathers. We will also learn that if you were ever to get lost in the jungles near the Satpura hills of Madhya Pradesh, we should make our way to the Sembar tree, for good spirits live there, glowing like gold in the night.

Through their art, they provide a fascinating and haunting foray into the imagination, in which the aesthetic and spiritual aspects of the world are inseparable.

\section{Technique:}

Gond Tribal paintings of Madhya Pradesh were mostly done on the walls of the houses. These paintings begin from the base of the wall and reach up to the height of eight to ten feet. The surface is prepared for painting by plastering the wall with black or white colored clay and cow-dung mixture. This clay in vernacular is called garu or gar. After the wall dries up, painting is done with the help of a cotton swab or piece of cloth tied to the twig of neem or babul tree. The colors used were mostly white, black, blue, yellow or saffron and these were obtained from vegetables or locally available clay or stone.

Paper and canvas are the new media of storytelling for the painters. A rough pencil outline first forms the premise for the visual narratives. Once bright acrylic colors have filled the canvas with flat expanses, small patterns evocative of tattoos worn by the womenfolk begin to emerge. Like undulations of song, like fables within tales, colorful dots and lines chase each other in close succession. Immense patience and delicate brush strokes are part of the meditative process, as if reminiscing the days past. Nature is and always will be loved on the canvas, as tigers, deer, snakes, cattle and birds merge with each other and with contorting trees on the seemingly psychedelic 
representations. Seemingly so, because the songs that spoke about the vivid characters, the deities and demons have almost been silenced and the colours try to break out of the canvas to tell the beholder what a wonder Mother Nature is. These paintings are figurative in design and sketch various forms of birds, animals, humans, gods, goddesses, depicting man-nature relationship. Social customs, religious beliefs and tribal worldview find reflection in these paintings.

Traditionally, the artists used natural colors derived from locally available minerals, charcoal, colored soil, plant sap, leaves, cow dung, clay, vegetables and stones. Today poster colors, acrylic and oil paints are also being used. New motifs like cycles, aero planes, motorcycle, jeep, bus, guns all find home in Gond paintings, demonstrating the contemporaneity and dynamic character of folk paintings.

At present, there are a number of artists who - through their paintings of the Gond way of life are generating an interest in these traditions. For the most part these artists are Gond Pardhans, one of the branches of Gond community. Jangarh Singh Shyam was the first Gond Pardhan artist to come into focus during the inception of Bharat Bhawan, Bhopal. The present genre of Gond painting is now called JangarhKalam.

This is an attempt to trace the Gond cultural tradition through the artist's eye as it captures different planes of Gond art, their philosophies, their delights, struggle for asssimilation, affiliation with nature, myths, tales and lore.

\section{Futuristic Approach ofColors:}

The Gonds have already migrated away from indigenously developed pigments to art supplies readily available in the market. This happened in a sudden discovery by late artist J. Swaminathan in the 1980s during the development and inception of Bharat Bhawan in Bhopal. This event marked the birth of 'JangarhKalam' - an entirely new genre of painting with its roots in Gond Tribal tradition, and its presence parallel to the contemporary arts. He transferred the art from dung covered walls of Patangarh village, Dindori District Madhya Pradesh to a milieu of mediums and bases like poster colors \& acrylics on Paper, ink on paper, acrylic on canvas, and depicted huge murals on walls of many government buildings in India and abroad.

His legacy has been faithfully carried forward by members of his kith and kin. Usually executed in bright primary colors, recently, some Gond artists have taken up somber hues of black and white especially using pen and ink as their chosen medium.

It has been close to 35 years since Jangarh Singh Shyam first picked up paintbrushes and paper to create his legacy. Moving forward, the researcher is of the opinion that indigenously made pigments and handmade base for the Gond Tribal Art will assist in retaining the traditional flavor of the art. However, readily available mass produced art supplies are more convenient to obtain and execute. Currently, the selection and colour composition of various hues are independent of various techniques elaborated by classical arts. The Gond Tribal Art reflects the innocence of a child while selecting primary colors to create bright, multi-hued paintings regardless of tonal balance, color harmonies or the like. It depends on the current and future generation of Tribal 


\section{INTERNATIONAL JOURNAL of RESEARCH -GRANTHAALAYAH \\ A knowledge Repository}

Art

artists how they will carry the legacy forward. Whether they will retain the current predicament of applying primary color blocks with patterned decorations in their narratives of history and challenging modernity. Whether they will go back to the cumbersome process of making handmade pigments, and developing original handmade papers etc to giveGond Tribal Art an originality hard for novices to match, or continue in the use of commercial art supplies and incorporate contemporary approaches to color harmonies and composition to come in line with mainstream art. Only time can tell what the future holds for us.

\section{Conclusion:}

Affluent in color, humor, detail and mystery, tribal art has an immediacy that few other art forms can claim. In the words of the artists themselves, they believe it to be a celebration of their own existence.

Red, yellow, black, blue, green, purple and white are the main colors used. Boasting of a vivid and lively colour palette, most Gond paintings are as dynamically hued as the artists' positive approaches towards life. Compositions are bright and cheerful inducing a festive and bright emotion in the viewer.

\section{REFERENCE:}

1. J Swaminathan, 'Submerged Archipelago', orig. in Swaminathan ed., The Perceiving Fingers, catalogue of the Roopankar Museum (Bhopal: Bharat Bhavan, 1987), p. 8.

2. John Bowles, 'Songlines from the Museum of Man' (Tehelka, New Delhi, 28 January 2006) http://www.tehelka.com/story_main16.asp?filename=hub012806Songlines.asp

3. Sheikh Gulab, The Gondsrpt. in Vajpeyi U. 'JangarhKalam 'Narrative of a tradition Gond Painting (Bhopal, 2008), p. 60.

4. UdayanVajpeyi and Vivek, JangarhKalam/ Narrative of a Tradition - Gond Painting (Bhopal: VanyaPrakashan/ Department of Tribal Welfare, Government of Madhya Pradesh, n. d. [2006]).

5. ignca.nic.in 